\title{
Dolor epigástrico postural como posible síntoma exclusivo de gastritis por citomegalovirus en pacientes trasplantados renales: presentación de un caso
}

\author{
Epigastric Pain related to Posture as a Possible Symptom of Gastritis due to \\ Cytomegalovirus in a Renal Transplant Patient: A Case Report
}

\author{
Mónica Zuluaga-Quintero, MD, ${ }^{2}$ Arbey Aristizábal-Alzate, MD, ${ }^{1}$ John Fredy Nieto-Ríos, MD, ${ }^{1}$ Catalina Ocampo-Kohn, MD, ${ }^{1}$ \\ Lina María Serna-Higuita, MD, ${ }^{1}$ Juan Camilo Pérez-Cadavid, MD, ${ }^{3}$ Gustavo Adolfo Zuluaga-Valencia, MD. ${ }^{1}$
}

1 Nefrólogo, Hospital "Pablo Tobón Uribe". Universidad de Antioquia. Medellín, Colombia

2 Residente de Medicina Interna. Universidad Pontificia

Bolivariana. Medellín, Colombia

3 Patólogo, Hospital “Pablo Tobón Uribe”. Medellín, Colombia

Fecha recibido: $\quad 12-02-15$

Fecha aceptado: 21-07-15

\begin{abstract}
Resumen
La enfermedad por citomegalovirus es una entidad con importante morbilidad y mortalidad en pacientes trasplantados de órgano sólido, que se puede presentar como primoinfección o reactivación y con manifestaciones clínicas muy variables. A continuación se reporta el caso de un paciente con dolor epigástrico intenso postural como síntoma inicial de primoinfección por citomegalovirus.
\end{abstract}

\author{
Palabras clave \\ Citomegalovirus, trasplante renal, gastritis, dolor epigástrico.
}

\section{Abstract}

Cytomegalovirus is an entity which causes significant morbidity and mortality among solid organ transplant patients. It may occur as a primary infection or be reactivated. In either case clinical manifestations vary. We report the case of a patient with severe epigastric pain related to posture which was the primary symptom of a cytomegalovirus infection.

Keywords

Cytomegalovirus, renal transplantation, gastritis, epigastric pain.

\section{INTRODUCCIÓN}

La enfermedad por citomegalovirus (CMV) constituye una complicación importante en los pacientes trasplantados de órgano sólido, con alta morbilidad y mortalidad asociada con los efectos citopáticos del virus y sobre el sistema inmunológico (1).

El diagnóstico de enfermedad por CMV se realiza cuando hay signos o síntomas asociados con el virus con evidencia de invasión tisular y aislamiento del virus por diferentes técnicas (2). Se cataloga como primaria cuando se detecta en un individuo previamente seronegativo o por reactivación en pacientes que portan el virus o tuvieron una infección anteriormente tratada que recurre. Las manifestaciones clí- nicas pueden ser variadas e incluyen síntomas como fiebre, astenia, hiporexia, dolor abdominal, diarrea, vómito y cefalea. Dentro de los estudios puede encontrarse leucopenia, trombocitopenia, hiponatremia y evidencia de compromiso visceral. Se debe tener un alto índice de sospecha de esta entidad en el período postrasplante, donde el compromiso gastrointestinal es el más frecuente $(1,2)$. Se ha descrito una útil manifestación clínica de la enfermedad, que incluso ha sido reconocida por la Sociedad Británica de Trasplante (3), $y$ es el dolor epigástrico postural como síntoma de enfermedad por CMV y que se atribuye a la gastritis por CMV. A continuación se presenta el caso de un hombre con infección por CMV a los 5 meses postrasplante que tuvo como síntoma principal el dolor epigástrico postural. 


\section{CASO CLÍNICO}

Paciente masculino de 64 años de edad con antecedentes de hipertensión arterial, diabetes mellitus, obesidad, dislipidemia y enfermedad renal crónica terminal manejada con hemodiálisis. Fue trasplantado de riñón de donante cadavérico en marzo de 2014; recibió inducción con basilixi$\mathrm{mab}+$ bolos de metilprednisolona, mantenimiento inmunosupresor con tacrolimus (niveles objetivo $4-7 \mathrm{ng} / \mathrm{mL}$ ), micofenolato sódico $720 \mathrm{mg}$ /día y prednisona $10 \mathrm{mg}$ /día; serología IgG para CMV negativa y donante con serología CMV IgG positiva; recibió profilaxis con valganciclovir durante 100 días. Ingresó a los 5 meses y medio postrasplante refiriendo 4 días de evolución de dolor abdominal epigástrico intenso, tipo urente y punzante, que empeoraba al estar de pie y al caminar y que mejoraba con el decúbito supino; al examen físico solo se encontró dolor a la palpación de epigastrio sin signos de irritación peritoneal. Ante este cuadro, múltiples diagnósticos diferenciales fueron descartados: al comienzo se pensó en un evento coronario agudo; sin embargo, el dolor no era típico de angina, no hubo compromiso de la saturación de oxígeno y el electrocardiograma y biomarcadores fueron negativos, se realizó además ecocardiograma sin alteraciones en miocardio o pericardio, ecografía de abdomen con vesícula sin cálculos e hígado de tamaño normal, virus de hepatitis B y C negativos y perfil enzimático normal (amilasas, lipasas y deshidrogenasa láctica), con lo que se descartó pancreatitis, colecistitis, y hepatitis; además, la radiografía de tórax no mostró signos de consolidación que sugiriera un dolor referido por neumonía ni cambios en mediastino o grandes vasos que explicaran una patología aórtica, sin embargo llamaba la atención el aumento en las transaminasas y la presencia de leucopenia, trombocitopenia y disfunción renal (tabla 1) lo cual, asociado con el dolor abdominal referido, el tiempo de trasplante y la serología para CMV conocida del donante y el paciente, hizo sospechar de una infección oportunista. Se realizó entonces, carga viral para CMV que fue positiva con 106900 copias/mL y endoscopia digestiva superior que reportó gastritis erosiva antral, con biopsia cuya patología mostró inflamación aguda de la mucosa e inmunohistoquímica positiva para CMV (figura 1). Se inició tratamiento con ganciclovir intravenoso (IV), ajustado al peso y función renal, con mejoría de los síntomas a la semana de iniciado el tratamiento y se completó durante 21 días con resolución del cuadro clínico.

\section{DISCUSIÓN}

La infección por CMV es la infección oportunista más frecuente en el trasplante renal, siendo el momento habitual de aparición en los primeros 6 meses (tiempo en el cual se recibe la dosis acumulativa máxima de inmunosupresión); aunque se puede presentar durante cualquier momento de la evolución (1). Se manifiesta de 3 formas: infección primaria, cuando no ha existido contacto previo con el virus y se recibe de un donante seropositivo o por trasfusiones de sangre; reactivación, cuando el trasplantado seropositivo desarrolla la enfermedad por el efecto de la inmunosupresión; y sobreinfección, donde el receptor seropositivo adquiere una cepa diferente de un donante seropositivo. La importancia de su sospecha y reconocimiento temprano radica en su relación directa con un aumento en la morbimortalidad $(2,3)$.

Tabla 1. Paraclínicos.

\begin{tabular}{|c|c|}
\hline Examen & Resultados \\
\hline $\mathrm{Hb}$ & $12,7 \mathrm{~g} / \mathrm{dL}$ \\
\hline Hematocrito & $37 \%$ \\
\hline Leucocitos & $3400 \mathrm{~mm}^{3}$ \\
\hline Neutrófilos & $68,9 \%$ \\
\hline Linfocitos & $19 \%$ \\
\hline Plaquetas & $60000 \mathrm{~mm}^{3}$ \\
\hline PCR & $1,17 \mathrm{mg} / \mathrm{dL}$ \\
\hline Creatinina & $1,78 \mathrm{mg} / \mathrm{dL}$ \\
\hline BUN & $22,2 \mathrm{mg} / \mathrm{dL}$ \\
\hline $\mathrm{Na}$ & $141 \mathrm{mmol} / \mathrm{L}$ \\
\hline Potasio & $3,9 \mathrm{mmol} / \mathrm{L}$ \\
\hline Calcio & $8,1 \mathrm{mg} / \mathrm{dL}$ \\
\hline Fósforo & $3,6 \mathrm{mg} / \mathrm{dL}$ \\
\hline Cloro & $107 \mathrm{mmol} / \mathrm{L}$ \\
\hline Amilasas & Negativo \\
\hline AST & $47 \mathrm{U} / \mathrm{L}$ \\
\hline ALT & $54 \mathrm{U} / \mathrm{L}$ \\
\hline $\mathrm{LDH}$ & $334 \mathrm{U} / \mathrm{L}$ \\
\hline Glucemia & $75 \mathrm{mg} / \mathrm{dL}$ \\
\hline Niveles de tacrolimus & $4,8 \mathrm{ng} / \mathrm{mL}$ \\
\hline Fosfatasa alcalina & $84 \mathrm{U} / \mathrm{L}$ \\
\hline Carga viral para CMV & 106900 copias por mm $\mathrm{mm}^{3}$ \\
\hline
\end{tabular}

ALT: alanino aminotransferasa; AST: aspartato aminotransferasa; BUN: nitrógeno ureico en sangre; $\mathrm{CMV}$ : citomegalovirus. $\mathrm{Hb}$ : hemoglobina; LDH: lactato deshidrogenasa; PCR: proteína C-reactiva.

El CMV produce un cuadro clínico variable e inespecífico que puede confundirse con múltiples condiciones clínicas, lo que hace difícil su diagnóstico inicial: generalmente el comienzo es insidioso y la fiebre suele ser un síntoma clásico, sobre todo si su evolución es prolongada (hasta 3-4 semanas), sumada a manifestaciones generales como astenia, adinamia, mialgias y artralgias (3); sin embargo, no existe un hallazgo típico que permita alertar 


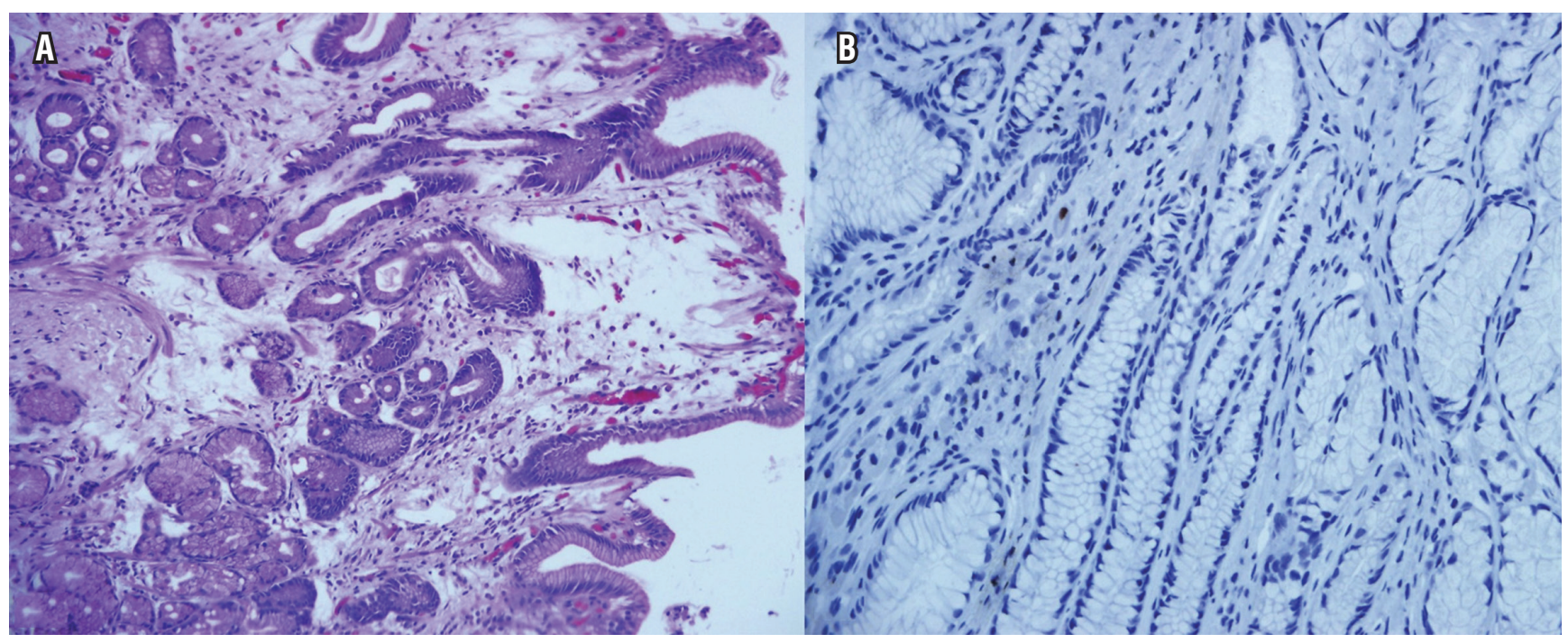

Figura 1. A. Biopsia gástrica: hematoxilina eosina 200x mucosa gástrica antral con edema y leve infiltrado inflamatorio mononuclear. B. Inmunohistoquímica positiva para citomegalovirus en algunas células endoteliales de la lámina propia.

su sospecha. Un signo de laboratorio común es la presencia de citopenias, pues hasta en el 50\%-60\% de los casos puede causar anemia, trombocitopenia, leucopenia o su combinación; puede presentarse afección multiorgánica con compromiso hepático, respiratorio, renal, cerebral y gastrointestinal pero en menor porcentaje (hasta en el 30\% de los casos); sin embargo, la disfunción del injerto renal aislado o en conjunto con otros signos es más frecuente, encontrando alta incidencia de rechazo agudo ante la presencia de este oportunista (1). No obstante, las manifestaciones gastrointestinales siguen siendo las más prevalentes, donde cualquier parte del tracto gastrointestinal puede afectarse presentándose dolor epigástrico, nauseas, vómito, diarrea, ulceraciones, hemorragia digestiva o perforación $(2,4)$. Los hallazgos endoscópicos característicos (eritema difuso, erosiones, nódulos, placas y úlceras) ayudan en su sospecha junto con las pruebas serológicas; pero la histología que reporta cambios citopáticos y su confirmación con carga viral sigue siendo la prueba de oro $(2,5,6)$.

La dificultad que existe con el diagnóstico obliga a buscar estrategias de sospecha oportuna, donde lo más importante es categorizar por riesgo (si es alto o bajo) y con base en la clínica, solicitar estudios para su confirmación. Se consideran de bajo riesgo situaciones donde el donante $y$ el receptor son seronegativos y de alto riesgo cuando el donante es seropositivo para un receptor con serología negativa sumado al tipo de inmunosupresión instaurada, el tiempo de trasplante, los contactos, las comorbilidades y la profilaxis antiviral utilizada (1). Si estas últimas situaciones están presentes y existe sospecha clínica, se deben realizar estudios serológicos que permitan determinar la infección primaria y biopsia de lesiones con cultivo asociada con carga viral para el seguimiento de la respuesta al tratamiento; esto independiente de la probabilidad diagnóstica de otra patología, puesto que esta infección oportunista tiene un alto margen de confusión y un tratamiento antiviral temprano tiene altas tasas de éxito y efecto directo en la sobrevida del paciente y del injerto (2).

En nuestro paciente, llamaba la atención que refería el dolor epigástrico con características particulares como el aumento del mismo al estar de pie o caminar y mejoría con el decúbito supino; esto no se consideró como una manifestación exclusiva de alguna entidad y se debieron descartar todas las posibilidades anteriormente mencionadas. Finalmente, se diagnosticó compromiso gastrointestinal por CMV y se dio el tratamiento adecuado con mejoría de la sintomatología. Basados en este hallazgo, se encontró en la literatura descripciones de dolor epigástrico postural como una manifestación de gastritis por CMV, hasta ahora 7 casos reportados en pacientes trasplantados de órgano sólido, 6 de ellos renal, con primoinfección o reactivación por CMV, todos confirmados con estudio endoscópico e histología y resolución de este síntoma al completar el tratamiento.

Los primeros casos los publican Giladi y colaboradores (5): 3 pacientes que, luego de 3 meses postrasplante, presentaron dolor epigástrico que se incrementaba en la bipedestación, al caminar y que disminuía en supino; en todos se documentó primoinfección por CMV y hubo resolución completa del dolor y demás síntomas después del tratamiento antiviral. Igualmente en el 2006, Moustafellos P y colaboradores (6) describen el caso de una mujer con primoinfección por CMV que consulta a las 6 semanas postrasplante con dolor en epigastrio que aparecía al sentarse y caminar y cedía con el descanso en cama, síntoma 
que resolvió a la segunda semana de haber iniciado el tratamiento con ganciclovir. El reporte 3 años después de Li Wy colaboradores (7) describe la misma situación en un hombre joven con infección por CMV, 4 meses postrasplante, que refirió este síntoma durante 1 semana previo a su consulta y se resolvió a las 2 semanas de iniciar tratamiento con ganciclovir; en este caso ambos, donante y receptor, fueron seropositivos para CMV, lo que sugiere que no es un signo exclusivo de primoinfección. Tapan y colaboradores (8) reportan el caso más reciente publicado, un hombre de 36 años de edad que también presenta dolor epigástrico postural y se confirma la presencia de gastritis por CMV en la biopsia. Nosotros publicamos el caso de un hombre en posoperatorio de trasplante renal que presentó el dolor epigástrico postural como el primer síntoma de esta patología.

Otras enfermedades pueden cursar con dolor epigástrico, pero en ninguna se ha descrito la exacerbación de los síntomas con la postura como la característica principal, más aun cuando en algunas de ellas el dolor se intensifica con el supino. En los pocos casos descritos hasta ahora, este síntoma se ha documentado durante la fase activa de la infección gastrointestinal por CMV y se ha resuelto luego del tratamiento antiviral. Con base en lo anterior se sugiere que el dolor epigástrico postural puede ser una manifestación exclusiva de infección por CMV en trasplantados renales, aunque solo hay pocas descripciones y no se puede determinar una conclusión universal; la mayoría de veces puede no ser expresado de manera espontánea por el paciente y por tanto debe ser interrogado específicamente al respecto, sugiriendo el diagnóstico de gastritis por CMV, pero siempre debe confirmarse con la realización de estudios serológicos, endoscopia y biopsia.

\section{CONCLUSIÓN}

El dolor epigástrico postural intenso es un síntoma clínico que puede sugerir compromiso gástrico por CMV en pacientes trasplantados de órgano sólido sobre todo, pero no exclusivamente, durante la primoinfección. Se sugiere descartar esta entidad ante la presencia de este síntoma, que puede ser la única manifestación inicial; sin embargo, el diagnóstico diferencial es amplio y complejo, por lo que se deben realizar todos los estudios necesarios para descartar otras entidades que puedan colocar en peligro la integridad del paciente.

\section{REFERENCIAS}

1. De la Torre J, Farinas M, Castón J, Aguado J, Cantisá S, Carratalá J, et al. GESITRA-SEIMC/REIPI recommendations for the management of cytomegalovirus infection in solid-organ transplant patients. Enferm Infecc Microbiol Clin. 2011;29(10):735-58.

2. Kotton C, Kumar D, Caliendo A, Åsberg A, Chou S, Snydman D. International Consensus Guidelines on the management of cytomegalovirus in solid organ transplantation. Transplantation. 2010;89(7):779-95.

3. Guidelines for the prevention and management of cytomegalovirus disease after solid organs transplantation. $3^{\text {rd }}$ edition. British Transplantation Society; 2011.

4. Linares L, Sanclemente G, Cervera C, et al. Influence of cytomegalovirus disease in outcome of solid organ transplantpatients. Transplant Proc. 2011;43(6):2145-8.

5. Giladi M, Lembo A, Johnson B Jr. Postural epigastric pain: A unique symptom of primary cytomegalovirus gastritis? Infection. 1998;26:234-5.

6. Moustafellos P, Hadjianastasiou V, Gray D. Postural epigastric pain as a sign of CMV gastritis: A case report. Transplant Proc. 2006;38(5):1357-8.

7. Li W, Fan H, Yiping L. Postural epigastric pain as a sign of cytomegalovirus gastritis in renal transplant recipients: A case based review. Transplant Proc. 2009;41(9):3956-8.

8. Tapan U, Kutlugun AA, Arici M, Altun B. Postural epigastric pain: A challenging symptom for cytomegalovirus (CMV) gastritis. Ren Fail. 2012;34(2):235-6. 